\title{
Wifehood (Im)politeness in Negotiating Responsibility, Position, and Solidarity in Ola Rotimi's Our Husband Has Gone Mad Again
}

\author{
Ezekiel Opeyemi Olajimbiti \\ Department of English and Literary Studies \\ Federal University, Lokoja \\ Nigeria \\ opebukola56@gmail.com
}

\begin{abstract}
This study examines how wifehood is discursively practiced in Yorùbá traditional polygamous marriage system as portrayed in Ola Rotimi's Our Husband Has Gone Mad Again. Purposively, excerpts involving the three wives of the major character, Lejoka Brown were basically sampled from the text. Through the instrumentality of politeness and impoliteness theories the study has unpacked the negotiation of responsibilities among wives in discharging their wifehood, where language is discursively used politely and impolitely based on the display of native competence and incompetence of the personalities involved. The study unveils hatred, unverified assumption, ignorance, anger and misconception as emergent factors that usually birth rivalry in wifehood negotiation of position that characterised impoliteness and family dysfunction in the rich verbal sociocultural setting. The study underscores the peaceful coexistence of wifehood within family discourse as a contribution to solving unhealthy marital issues characterised by linguistic politeness and impoliteness that pervade the contemporary society.
\end{abstract}

\section{Introduction}

This study focuses on how wifehood is performed in a polygamous family of Yorùbá traditional marriage system as portrayed in Ola Rotimi's Our 
Husband Has Gone Mad Again by examining the rivalry discourse between native wives and foreign wife. Wifehood, in this context, expounds on the ways in which women interact to negotiate a position and recognition in a polygamous family. In family discourse, culture, personality, religious belief, work roles, parental background, education attainment and physical environment are all important factors in determining peace or otherwise in any family. Meanwhile, as important as these factors are, so is the use of language that defines each. Thus, the linguistic composition of a family as effective communication goes a long way in uniting the family. Walsh (1998: 37) corroborates this that: "poor communication is considered by psychoanalysts to be to most recurrent and serious problem in ailing marriages." However, the concern of this study is to show how language is discursively used in negotiating power, position and recognition politely or impolitely within a polygamous family setting as an index of family harmony and dysfunction.

\section{Wifehood and African Traditional Marriage System}

The concept of wifehood has been scantly explored in the literature differently. Mulamba (2013: 49) describes wifehood as ways in which women construct their identity through discourse and the performance of their 'wife's duties'. In her view, Keiting (2010: 12) sees it from an ideological perspective. She explains wifehood as the dedicated wife, the state of auspicious wife and the true woman to her husband. Wilson (2000: 3) says that wifehood explains how two women, both wives, both mothers in domestic home front constitute marriage practice in the ideal traditional ideology of submission and obedience to their husband. Duman (2006: 9) relates wifehood to a picture in the discourse of marriage constructed upon the husband, home, and love. In all of these studies, wifehood has not been considered from the perspective of position negotiation within a polygamous marriage system. Neither has it been looked at from the linguistic purview where the utterances of wives considered politeness or otherwise.

African traditional marriage system believed in polygamous marriages because of its patriarchal characteristics. Kanyoro (2002: 78) argues that in the African context, before marriage, a woman did not have an independent identity. A woman was regarded as the daughter of her father. After marriage, she became the wife of her husband. Polygamy was accepted and seen in Africa as a sign of wealth. Burke (2010: 30 ) asserts that women were so used to polygamous marriage that sometimes the marriage of a second wife is provoked by the first wife who urges her husband to take a second wife to help her in the farm work. Criticizing this, Dangor (2001:15) argues that polygamy creates inequality amongst co-wives since the husband cannot care for and cater to the needs of more than one wife, and that polygamy gives men 'boundless power and authority.' 
Despite the polygamous system in the traditional Africa, African cultural traditions were cherished and protected because wives were submissive and seen as custodians of homes: home management and raising children were their sole responsibilities. The present study, therefore, attempts to investigate wifehood (im) politeness within a typical African traditional polygamous marriage system.

\section{Theoretical Orientations}

Two theoretical orientations foreground this study: Brown and Levinson's (1987) politeness theory and Culpepper's (1996) impoliteness theory. The choice of these two alternative linguistic theories is premised on the linguistic $\mathrm{x}$-ray of politeness and impoliteness of wives as they negotiate responsibility and position in the practice of their wifehood.

\section{Politeness Theory}

The politeness was first conceived in 1978 by Brown and Levinson as a departure from the cooperative principle of Grice. Politeness is captured in terms of conflict avoidance; thus politeness enhances communication between potentially aggressive parties. They came up with some politeness strategies which are categorized into positive and negative politeness strategies. The model revolves around the concept of face (Goffman, 1966: 102) which is defined as the public self-image that all members of the society have and seek to claim for themselves. Brown and Levinson (1987: 205) suggest that this image consists of two related aspects: negative face (freedom from imposition i.e. the desire for freedom from impingement) and positive face (the desire to be appreciated and approved of, i.e. the desire to be wanted). Positive politeness strategies address other's positive face wants, whereas negative politeness strategies address their negative face by showing distance and impersonality.

\section{Impoliteness Theory}

Impoliteness is elusive in nature, the reason for its interesting framework. Impoliteness according to Culpeper (2005: 55) is not something that is bluntly expressed because we cannot precisely read people's mind; rather the important thing here is the perception of intention. He further proffers the following as a description of impoliteness: first, when a speaker communicates face attack intentionally, second, when the hearer perceives and/or constructs behavior as intentionally face-attacking, while the third one is a combination of the first and second postulations (Culpeper, 2005:38). The two theories have different super-strategies to actualize their beliefs. For the purpose of this 
study, the strategies have been placed side by side on a table below to distinctly show their differences.

\begin{tabular}{|c|c|}
\hline Politeness & Impoliteness \\
\hline $\begin{array}{l}\text { Politeness is defined as using communicative } \\
\text { strategies to create and maintain social har- } \\
\text { mony. This can be done in various ways: } \\
\text { Being contextually appropriate }\end{array}$ & $\begin{array}{l}\text { Impoliteness is defined as engaging in aggres- } \\
\text { sive face-work in particular contexts to cause } \\
\text { social disruption. This can be done in various } \\
\text { ways: }\end{array}$ \\
\hline Following social and cultural norms & The speaker intentionally attacks the face \\
\hline $\begin{array}{l}\text { Being socially positive by addressing face } \\
\text { needs }\end{array}$ & $\begin{array}{l}\text { The listener perceives a face attack } \\
\text { Both of the above }\end{array}$ \\
\hline $\begin{array}{l}\text { In order to save face, people have the option } \\
\text { to use politeness super strategies with FTAs: }\end{array}$ & $\begin{array}{l}\text { There are also impoliteness super-strategies } \\
\text { which can be used with FTAs: }\end{array}$ \\
\hline $\begin{array}{l}\text { Bald on record is not attempting to mini- } \\
\text { mize the face threat }\end{array}$ & $\begin{array}{l}\text { Bald on record is an unmitigated intentional } \\
\text { face attack }\end{array}$ \\
\hline $\begin{array}{l}\text { Positive politeness is showing you value } \\
\text { someone so minimizing the threat to the } \\
\text { positive face }\end{array}$ & $\begin{array}{l}\text { Positive impoliteness is attacking the positive } \\
\text { face need by not showing you value someone. } \\
\text { Negative impoliteness is attacking the negative }\end{array}$ \\
\hline $\begin{array}{l}\text { Negative politeness is not impeding on } \\
\text { someone so minimizing the threat to the } \\
\text { negative face }\end{array}$ & $\begin{array}{l}\text { face need by imposing on someone } \\
\text { Off record is using indirect offence such as sar- } \\
\text { casm or banter }\end{array}$ \\
\hline $\begin{array}{l}\text { Off record is avoiding responsibility for the } \\
\text { FTA often by being indirect }\end{array}$ & $\begin{array}{l}\text { Without politeness is failing to be polite when } \\
\text { it is expected. }\end{array}$ \\
\hline $\begin{array}{l}\text { Withhold is not performing the FTA } \\
\text { Politeness super strategies are determined by } \\
\text { contextual factors }\end{array}$ & \\
\hline $\begin{array}{l}\text { Power relations between speaker and listener } \\
\text { Social distance between speaker and listener } \\
\text { How great the threat of the face threaten- } \\
\text { ing act is }\end{array}$ & \\
\hline
\end{tabular}

Table 1: Comparison of Politeness and Impoliteness Strategies 


\section{Methodology}

This study is based on Ola Rotimi's play Our Husband Has Gone Mad Again because of its spatial setting and its richness in the evocation of typical Yoruba traditional marriage system. Purposively, excerpts involving the three wives (Mama Rashida, Sikira, and Liza) of the major character, Mr. Rahman Lejoka Brown were basically sampled for the analysis. These excerpts were selected not only because they capture wifehood interactions as the focus of the discussion but, also, because they contain certain linguistic behaviors rich enough to track (im)politeness features. They are packaged in Act 1, Scenes II and III and Act 2, Scenes 1 and III. Insights were drawn from politeness and impoliteness theories as super strategies of both theories were employed in the investigation of wifehood discourse. The choice of the theories is justified because the selected interactions manifest face concepts. The analysis involves four levels where wifehood is discussed, which are woven around preparation for Liza's arrival, at Liza's arrival and three weeks after Liza's arrival. The four sections of the analysis are negotiation of responsibility in the context of domesticity, negotiation of attention in the context of hatred, negotiation of position in the context of identity clash, and negotiation of solidarity in the context of unity.

\section{Analysis and Findings}

The analysis is done at three levels in order to capture the wifehood practice in the text chosen for the study. These levels are the negotiation of responsibility in the context of domesticity, negotiation of attention in the context of hatred and negotiation of position in the context of identity clash, and negotiation of solidarity in the context of unity. All of these are the manifestations of display of rivalry in a polygamous marriage system projects in the selected text to foreground linguistically polite behaviors of Mama Rashida and impolite manners of Sikira and the oscillation of the two forms of behavior Liza, from a foreign culture, as to progressively negotiate.

\section{Negotiation of Responsibility in the Context of Domesticity}

This section discusses the wifehood negotiation of responsibility between Mama Rashida and Sikira within the context of domesticity in Yorùbá traditional marriage system, as the duo tidy up the house for the arrival of their husband's wife they will be welcoming home. Domesticity here relates to home management where a wife or wives is/are matrimonially responsible for keeping the home tidy. Within the framework of domestic responsibility enshrined by the Yoruba traditional culture, the duo are expected to collaboratively carryout this task with positive linguistic behavior. As the senior 
wife, Mama Rashida is empowered to give instruction as to how the house is kept. In this scene, Mama Rashida is seen cleaning up of the living room while an unconcerned Sikira is disrespectfully standing up and peeping out. This points out the nature of polite and linguistic impolite behaviors of Mama Rashida and Sikira respectively. The excerpt below expounds this.

Mama Rashida: [Sternly] Sikira!

Sikira: What is it?

Mama Rashida: The chairs, Woman, they need dusting... the window blinds, the chair covers must be...

Sikira: [Nonchalantly]. Aaahh

(she turns away to resume her gaze through the window.) ...

Mama Rashida: It is not for my wedding, nor for the memorial ceremonies for the departed Spirit of my forebears, that I am killing myself to get this house clean. Ooooh no, Woman! Our husband's wife is arriving this afternoon from America, and you know...

Sikira: $\quad$ Good news!

Mama Rashida: It is your duty, just as it is my duty, to make sure that when the woman steps into this house, she has no doubt that it is real human beings who live in it, and not bush pigs!

Sikira: I don't care what she thinks.

Mama Rashida: Unless you have no shame, you ought to care!

Sikira: $\quad$ Shame! My spit! (14-15). 
From the above, the responsibility of home management is negotiated with polite and impolite linguistic behaviors by the two wives involved. Politeness here relates to civility, good manners within the affordances of socio-cultural values that can be tracked from verbal behaviors and conversational norms. By implicature, the interactants' discourse is categorized into two attitudinal positions: the evocation of collaborative effort and display of indifference.

\section{Evocation of Collaborative Effort}

Evocation of collaborative effort indicates the act of alerting the attention of one's interlocutor to a concerted effort at getting a duty done within the appreciable time frame. From the excerpt above, Mama Rashida negotiates the responsibility of home management with Sikira by using three politeness strategies: positive politeness, off-record politeness, and bald on record politeness in calling for a collaborative effort. Positive politeness captures a situation of showing value to someone by minimizing the threat to positive face (self-esteem). As the senior wife, she has the audacity to command Sikira as empowered by the culture, but she is seen working while Sikira was engrossed in peeping. Calling Sikira to order here using positive linguistic behavior is presenting to Sikira what is left undone even as she continues with her work (a collaborative effort). "The chairs, woman." She uses honorific term so as to make Sikira feel important, and in turn, she will do what is expected. Mama Rashida says: "they need dusting...the window blinds, the chair covers must be..." in lines 3 and 4. This shows Mama Rashida as a responsible wife and also negotiating responsibility with Sikira.

When she discovers that Sikira is still not showing any sense of responsibility, she employs the use of off-record politeness in lines 8-11. Here she tells Sikira the truth that she is not just involved in the work for her benefit. Mama Rashida is avoiding responsibility for the face threatening act by indirectly informing Sikira that she is not solely responsible for the cleaning, rather they should share the responsibility (concerted effort), even then, and Sikira still shows negative behavior as she feels unconcerned. What she said here would have been needless because of the shared situational knowledge that exists between the two housewives but for the irresponsibility, Sikira is displaying. Throughout the interaction, she displays negative linguistic behavior projecting negative impolite manner.

Again, Mama Rashida employs bald on record politeness in lines 13-16 when Sikira fails to display her native competence responsibility as a wife. "It is your duty, just as it is my duty" Mama Rashida has to say this to express her concern as a responsible wife in ensuring that the house is made to look different from bush pigs' house knowing the caliber of the person they are 
expecting (Liza). She argues further in line 18, "unless you have no shame, you ought to care!”

\section{Display of Impolite Attitude of Indifference}

This relates to an emotional state characterized by a lack of concern or interest in being involved in a duty. Also in the above excerpt, Sikira displays indifference like someone who lacks decency in wifehood responsibility. She becomes impolite as it is reflected in her attitude towards the cleanliness of the house. Within the context of Yoruba traditional marriage system, where the concept of "house-help" or maid is alien, Sikira is supposed to know that it is her duty to join her rival and senior wife, Mama Rashida, to put the house in order. In the excerpt above, Sikira displays positive impoliteness which is the use of strategy designed to damage the addressee's positive face wants (Culpeper, 1996:357). In lines 5 and 6, Sikira bluntly shows she is disinterested, unconcerned by ignoring Mama Rashida who apart from being a senior wife is older than her. Therefore, within Yoruba culture, this act is an impolite behavior which is not expected of a good wife if peace is to be maintained in the family.

When Mama Rashida reminds Sikira that the cleaning must be carried out because their husband's wife will be arriving from America, she simply responded that it is "good news." This is characterized as negative impoliteness, damaging Mama Rashida's negative face wants by using condescending words, a reflection that she is not taking her interlocutor seriously. Again, this implies ridicule and insult to Mama Rashida considering the asymmetry power relation that exists between the two interactants. In line 17, she says "I don't care what she thinks". Sikira disregards the politeness strategy by responding offhandedly. She fails to act politely as expected of her. Within framework, this falls short of the expectation of a good housewife.

\section{Negotiation of Attention in the Context of Hatred}

It is not a strange phenomenon for a wife or wives to struggle for their husband's attention in polygamous marriage situation where the unhealthy rivalry is not unexpected. Attention is captured in the mental concentration of feelings for or undivided interest or care of the husband in the spousal setting. In this context, Sikira expresses her fear that her husband may not care for her again with the imminent coming of another wife. In the process of negotiating for attention, she becomes impolite towards Liza whom she has not seen. Her impoliteness is captured in two categories: personality deformation and inferiority complex. 


\section{Personality Deformation and Inferiority Complex using Impolite Linguistic Behavior}

This relates to the process of making a person less human through some impolite utterances. Such utterances are hatred induced ones and rivalry motivated within the purview of polygamous marriage. Inferiority complex, on the other hand, is described as feelings of less worth or importance than the other person. In this scenario, personality deformation is informed by inferiority complex of Sikira by psychologically feeling unsecured; a show of timidity with the intending arrival of Liza. The excerpt below expounds on this.

Sikira: $\quad$ Will our husband care for me now that that Miss World is coming here?

Mama Rashida: [lost] Miss World?

Sikira: That black-white woman who spent her whole life roaming the streets of America

Mama Rashida: [shocked] Liza?

Sikira: $\quad$ Must I spell out her name?

Mama Rashida: May Allah have mercy on you!

(An old man carrying rife shuffles tiredly toward Lejoka-Brown's house]

Sikira:

Ha! I know her kind. They think because they've been to England or to America-Toronto, they think they can come kick everybody round and round Like a ...football. (15-16)

The excerpt above is centered on the display of hatred toward Liza. Hatred captures prejudice hostility or showing feelings of dislike for someone out of acrimony as expressed by in the above. In the above, Sikira raises a question about her status in the family because of the circumstances that surrounded 
her marriage and being barren. Mama Rashida consoles her and enjoins her to pray to Allah to send the right seed to her womb. Rather than commenting on the prayer, Sikira expresses hatred out of jealousy toward Liza. She refers to Liza she has not seen at all "Miss World" in a derogative manner. This act is insulting (name calling) within positive impoliteness (Culpeper 2012:8). By implication, she is already feeling inferior to Liza as she uses off-record impoliteness to describe Liza in lines 3 and 4: "That black-white woman who spent her whole life roaming the streets of America." She also becomes judgmental as she presumptuously attacks the personality of Liza as domineering by saying: “...can come kick everybody round and round like a ...football” Mama Rashida in contrast, displays modesty as evidenced in lines 2, 5, 7. "May Allah have mercy on you!"

In another excerpt,

Mustafa: [stopping at the door] Oh... how rude of me. [turns around]

What time is the young lady arriving?

Sikira: $\quad$ Young lady - ha! The witch is old enough to be my grandmother! (18).

Mustafa comes around visiting and in the process, gets to know that the family is expecting a new wife from America. He then shows concern by asking for the time she will arrive. Rather than answering the question, Sikira brings in her prejudice hostility by derogative calling Liza a 'witch' old enough to be her grandmother. This is positive impoliteness as she tries to tarnish Lisa's personality before Mustafa.

\section{Negotiation of Position in the Context of Identity clash Framed by $(\mathrm{Im})$ politeness}

Identity clash manifests where there is confusion in the social role and the personality of individuals in a social relationship; especially where everybody tries to show self and assert position. In defining identity, Fairhurst (2007:113) asserts that identity comes to be defined both by the way individuals act and what they say about themselves. In this situation, Liza just arrives 
from America, thinking that she is the only wife of Lejoka Brown, thereby perceives Mama Rashida and Sikira as maids. This is why there is a struggle for position and recognition as Liza, who Lejoka Brown legally married and other two wives, Mama Rashida whom he inherited and Sikira whom he married because of his political ambition, negotiate power. Mainly between Liza and Sikira, there seems to be a serious rivalry. This is explicated in the excerpt below.

Liza:

Listen, Mama, do me a favour, get someone to ... [urgently] Where's that boy?

Mama Rashida: Who? Polycarp?

Liza:

[calling] Poo-ly-ca-a-r-rp!

Mama Rashida: We sent him to the airport- you forget?

Liza:

Well then, get the kitchen-maid [indicating kitchen] in there to do it!

Mama Rashida: [sheepishly]. Who? You mean...Sikira?

Liza: [calling] Sikira!

[no anwer]

S-i-k-i-r-a!

Sikira: [calling from offstage]. What is it, o?

Liza: Come here, quick!

[Sikira comes, wielding a soup ladle. Dowdily clad in her work, a-day 
clothes shoeless and without her veil on, she is the very model of a meritorious kitchen maiden.]

Sikira:

[straight- faced]. Who called Sikira, o?

Liza:

[coaxingly) Sikira, honey, I've been on the plane for over ten hours. Just sitting...you know...one tired. Naturally, I need a rest.

Sikira:

[nonchalantly licking sauce on ladle with her tongue, and at the same time noisily sucking in air to balm the pepper-scorched tongue]. So?

Liza

Get that same out of my room, will you please?

Sikira:

Me! Without the master telling me to? K'abo! (23-24)

The excerpt features the sophistication of Liza who sees other women at home are maids and then tries to be bossy. She displays impoliteness as a result of her ignorance. In line 7, she directs Mama Rashida to inform Sikira to take away 'freedom' from the room she will sleep. She refers to her as the kitchen maid. Though Sikira did not hear, she has made up her mind to resist any attempt by Liza to kick her around like a football. The kinetics Sikira displays in line 17 when she comes out of the kitchen gives credence to this: "[straight- faced]. Who called Sikira, o?" Her unwillingness to be inferior to Liza informs the way she defensively resisted the errand Liza sends her in line 22. "Get that same out of my room, will you please?"in line 23, Sikira simply replies her thus: "Me! Without the master telling me to?" "Me!" implies, Liza does not have the felicity power to send her on such errand.

Liza: [coolly caustic] someone ought to have told you, my dear girl that it isn't Proper for a to go peeping into the bedroom of her master at night or at any other... [Mama Rashida and Sikira exchange glances. To them, Liza must be one thing Out of her mind]

Sikira Housemaid! [incensed to Mama Rashida] 
Did you hear that grasshopper? I told you she would come and kick everybody Round and round...

Liza: $\quad$ What did you say?

Sikira: $\quad$ Ooh hoo! [Girds her wrapper tightly, ready for a fight]

Come on! You say you are a doctor? I will show you who I am! [feigns a charge

At Liza. Mama Rashida hurries over and intercepts Sikira. They struggle]

Mama Rashida: patience, you, patience, I say...

Sikira: $\quad$ let go, Mama Rashida! That fowl wants her proud feathers plucked!

Liza: [rising] Now wait a minute!

Mama Rashida: Calm down!

Sikira: I'd rather die than let that cockroach kick me around!

Mama Rashida: I said calmly...

Liza: Who is a cockroach?

Sikira: Who is a housemaid?

Mama Rashida: [pinioning Sikira's arms behind her] Now you...calm that hot temper right now, or I'll hit you! 
Sikira: Didn't you hear what that antelope called me?

Liza: I'm sorry, there must be a...

Mama Rashida: Listen to that, she says she's sorry.

Sikira: I don't want to hear...

Mama Rashida: [whacking Sikira’s arm] Quiet! Ta-ta-ta-ta! What has got into you?

Sikira: $\quad$ First thing that mosquito did was land on my head, biting me all over the...

Mama Rashida: All right, that's enough- listen to what she has to say now, will you? Abah! (24)

From the above, it is obvious that Sikira does not take Liza's ignorance lightly, especially calling her a "housemaid." She evaluates this as impoliteness, an attack on her social identity face; which is an attack on the desire for acknowledgement of one's social identity or role status. In this case, Sikira is not recognized as a wife but a maid. She, therefore, responded by insulting Liza. According to Culpeper (2001), this is one of the six examples of common conventional impolite expressions. Sikira uses personalized negative vocatives in responding to the impoliteness of Liza. She calls Liza "grasshopper" in line 7. Sikira reminds Mama Rashida of her prediction that Liza would come and kick everybody round and round like a football.

Sikira is prepared for a fight, being aggressive as she replies Liza when she intends to confirm what Sikira has just said in line 10-12: "Ooh hoo! [Girds her wrapper tightly, ready for a fight] Come on! You say you are a doctor? I will show you who I am! [Feigns a charge at Liza. Mama Rashida hurries over and intercepts Sikira. They struggle]" again, in line 14, Sikira says "That fowl wants her proud feathers plucked!" This means that Liza is a proud fowl and that she will pluck her feathers. This implies that Liza's pride and dignity will be reduced to nothing. This is positive impoliteness. Sikira uses another vocative "cockroach" to describe Liza in line 17. Other vocatives are "antelope" 
and "mosquito." From the above, it is obvious that Sikira uses threat and dismissal as an offensive response to Liza's impoliteness.

In line 16, when Liza becomes reactional by asking who is a cockroach, Sikira gives a counter reaction asking her who is a housemaid. This projects a display of linguistic impolite behaviour by the duo. Mama Rashida remains a peacemaker as she prevents Sikira who is ready to put up a fight against Liza, which would have caused a domestic physical combat. Basically, Sikira should politely correct the ignorant Liza rather than becoming offensive but because of her prejudice hostility she already has toward Liza, she confronts her to prove she is not a local, inferior and good for nothing fellow. She tries to negotiate her position in the family by opposing Liza.

Liza: [impatiently] Sure, sure, sure...now that that's established, let's turn to the next point my dear women, six years ago, Mr Lejoka-Brown-er... Rahman Lejoka-Brown, that is...Mr Rahman Lejoka-Brown and I got married...

Sikira: [a grunt] Halleluya!

Liza: In court... [Holding out her ringed finger]... ring and all

Sikira: $\quad$ Ehen? Therefore! [singing to the tune of Bobby Benson's Tax Driver highlife. $\left.{ }^{*}\right]$

If you marry in Magistrate Court nko, I don't care. If you marry in American

Toronto, I don't care. Whether you wear all rings in this world o, I don't care

Whether you know book tele* you tire o, I don't care!

Mama Rashida: Sikira! 
Sikira: I've slept more nights with the master than you have, therefore...

Liza: More wh-at?

Sikira: $\quad$ More nights; therefore, by native law and custom, I hold a senior place in this house

Mama Rashida: Enough! Come now! [Shoves Sikira roughly out of the living-room]

To your room!

Liza: [blanky] Native law and what!

Sikira: [over her shoulder] Whether you like it or not! (25)

Liza after being verbally battered by Sikira becomes logical, as she demands information as to knowing the personalities of the two women she met at home. Here, she becomes polite by enhancing their positive face wants, referring to them as "My dear women." She says this to appeal to their positive face wants to gain their attention as she intends to inform them of her legal marriage with Lejoka Brown and to clear the air.

Sikira continues in her impoliteness, as she attacks Liza's equity rights using negative impoliteness by invading her space through the interruption in line 4. Also, in lines 6-9, she uses condescension to trivialize Liza's fact impatiently. Additionally, in line 11, she uses without politeness strategy of boosting, deliberate aggression in line 13 and enforcement of role in line 17.

Mama Rashida: [kneeling beside Liza] Sister, I beg of you... do not let anger turn your head inside out. Have patience, I pray you. Come...with me to kitchen and get some salt and pepper in your stomach. [extends her hand to Liza] come sister...you can think over while you are eating. 
Liza: Think things over! Oooh no. there's nothing...totally, clearly, absolutely... [Hysterically]... nothing to think over, Mama. I cannot... repeat: cannot, I Cannot and will never surrender my person to be devoured in this ... blatantly decadent, third-rate domestic circus! Nor will I ever condescendto sharing the same monster of a husband with that...that... [points towards rear-rooms after Sikira] ...that smutty, ill-bred, foul-mouthed, uncouth, mangy, grossly ribald, whipper-snapper of a chipmunk!

Mama Rashida: [mild protest] Now, now, the master is not a monster!

Liza: I don't care what he... [stops abruptly for a full appraisal of Mama Rashida]

Who are you, by the way?

Mama Rashida: Who-me?

Liza: $\quad$ Yes -you. (26-27)

The thrust of the above excerpt is emotion display. By emotion, I mean a conscious reaction accompanied by physiological, behavioral actions and verbal expressions. Maintaining her role, Mama Rashida remains a peacemaker and an encourager. In the above, she encourages Liza not to display anger but to be patient and eat to pacify her anger in lines 1-4. She displays a high level of politeness as she kneels before Liza as a sign of regard. Within the Yoruba cosmological belief, apart from serving punishment, kneeling down is a great sign of respect and an index of politeness. The age disparity between Mama Rashida and Liza does not permit Mama Rashida to kneel before Liza, but for her to pacify anger emotion of Liza at this moment, she kneels before her. Also, her physical gesture of extending her hand to Liza also gives credence to her polite way of pacifying Liza in line 3 .

Liza, however, chooses to be impolite because of her anger as she raises verbal attacks on the family setting, reducing it to "third-rate domestic circus!" in line 8 . She also attacks the quality face want of Mr. Lejoka Brown by 
calling him "monster of a husband" and the quality face of Sikira by insulting her through the usage of personalized vocatives like " smutty", "ill-bred", "foul-mouthed", "uncouth", "mangy", "grossly ribald", "whipper-snapper of a chipmunk!" All these show how Liza displays her aggression. She also uses without politeness expression in line 13 by saying "I don't care what he..." to show the height of her emotion.

\section{Negotiation of Solidarity in the Context of Unity Characterized by Linguistic Politeness}

This section is characterized by peaceful coexistence among the three wives when the identity of each person is known and each positive face want is not threatened as a way of achieving solidarity. The initial misconception and rivalry conflict had disappeared.

Liza:

E-x-actly! [Mama Rashida swoops up to Liza and embraces her gratefully, Then kneels in prayer arms up-raised]

Mama Rashida: Heey! My sister, may Allah grant you His blessing. May Allah fill your womb with children-plenty, plenty children until your supply becomes greater than demand! [Liza, flabbergasted, burst out laughing. Sikira joins in; so does Mama Rashida who has returned to the business with her eggs]

Sikira:

Hm! You know, Sisi Liza, I was afraid when I heard you were coming from America, o!

Liza: Why? You didn't even know who I was. [proffers clothing to her] Here-try this on... [Sikira holds out clothing at arm's length, admiring it...]

Sikira:

Well...they say when our African women go to England, or to America, or So-so-so and-so, they come back wanting to be Headmasters, kicking Everybody round and round. 
Mama Rashida: [teasing] Now, now- don't feel too safe; Sisi Liza has been with us now Only three weeks.

Liza:

That's right, Mama Rashida. [to Sikira, jocularly] see? How do you know I won't kick you 'round and round' like a headmaster yet! (48)

From the above, Liza becomes a channel of blessing to the other wives. Therefore, the excerpt is characterized by commendation, laughter, confession, and teasing. These are features of solidarity that now exists among the trio. Commendation captures an act of praising someone who has done something worthwhile. Mama Rashida is full of praises and commendation to Liza who has helped her refurbish her poultry business as seen in lines 3-4. Laughter describes an act of expressing happy feeling when the atmosphere warrants it. The trio display this in lines 6 and 7 as amused by the prayer of Mama Rashida who prays that Allah will bless Liza with "children-plenty, plenty children until your supply becomes greater than Demand!" Confession is an act of making a statement that you have done something wrong. Here, Sikira confesses to Liza thus: "Hm! You know, Sisi Liza, I was afraid when I heard you were coming from America, o!" in lines 8 and 9. Now that the atmosphere is friendly, Sikira confesses why she was impolite initially. Teasing involves expression that does not show that one is completely serious and in some cases, it amuses joke or laughter. In other words, Sikira's confession shows she now has trust in Liza and feels secured. Then Mama Rashida teases her by saying: "Now, now- don't feel too safe; Sisi Liza has been with us now only three weeks." Liza also comments on this in lines 17 and 18.

\section{Conclusion}

The study has explored how language is discursively used in the wifehood communication within Yoruba traditional polygamous family system as portrayed in Our Husband Has Gone Mad Again. I have unpacked that in negotiating responsibilities among wives language is discursively used politely and impolitely based on the display of native competence and incompetence of the personalities involved. Mama Rashida portrays herself as a real traditional African woman who is tolerant, peaceful, submissive and respectful not only to her husband but also to her co-wives. Sikira is an intolerant wife in a polygamous system that only cares about her position and recognition evidenced in her linguistic behaviour. The study aligns with Mulamba (2013) and Wilson (2000) who see wifehood as the performance of duties and ideologies of submission and obedience of wives to their husband. It also shares the view with 
Dangor (2001) that polygamy creates inequality amongst wives as displayed by the tripartite wives in the current study how they negotiate position in the context of identity clash. Beyond that, this study has also shown that hatred, unverified assumption, ignorance, anger, and misconception usually birth rivalry in wifehood that characterised impoliteness and family dysfunction. The study also established that peaceful coexistence in wifehood enhances individual ability and success and family harmony that is characterised by commendation, laughter, willful confession and teasing that amuses jokes. All of these manifestations are unearthed through politeness and impoliteness strategies within family discourse. This attempts a significant contribution to solving unhealthy marital issues characterised by linguistic politeness and impoliteness that pervade the contemporary society.

\section{Bibliography}

Brown, P, and Levinson, S. Politeness: Some universals in language usage. Cambridge: Cambridge University Press, 1987.

Burke, M. "Marriage and family in Africa. Approaches in the light of National Values and of Modern Secular Attitude." 2010. Position papers.www. cormacburke.

Culpeper, J. "Towards an anatomy of impoliteness." Journal of Pragmatics 25, (1996):349-367.

------. Language and Characterisation: People in Plays and Other Texts. Cambridge: Cambridge University Press, 2001.

2005. "Impoliteness and Entertainment the Television Quiz Show: The Weakest Link." Journal of Politeness Research 1 (2005):35-72.

Dangor, S. "Historical Perspective, Current Literature and an Opinion Survey among Muslim Women in Contemporary South Africa: A Case Study." Journal of Muslim Minority Affairs 21.1 (2001):109-129.

Duman, D. "Discursive Construction of Female Image in Turkish Women's Magazines: A Socio-historical Approach to Critical Discourse Analysis." Ph.D. Dissertation. Hacettepe University, Ankara, 2006.

Fairhurst, G. T. 2007. Discursive Leadership: In Conversation with Leadership Psychology. Thousand Oaks, CA: Sage, 2007.

Goffman, E. Interaction ritual: essays on face-to-face behaviour. New York: Multilingual 8 (1966):101-129.

Kanyoro, M. Introducing feminist cultural hermeneutics: An African perspective. Cleveland: Pilgrim, 2002.

Keiting, M.W. Thinking about Wifehood in Heroic Wives Rituals, Stories and the Virtues of Jain Wifehood. London: Oxford University Press, 2010.

Leech, G. Principles of pragmatics. London: Longman, 1983. 
Mulamba, N. Luba Folklore and Women's Ethno-gendered Discourse of Wifehood in "Cintu Wa Bujitu". Afrika Focus. 26.2 (2013): 47-79.

Ola Rotimi. Our Husband Has Gone Mad Again. Ibadan: Oxford University Press, 1977.

Walsh, F. Strengthening Family Resilience. New York: The Guilford Press, 1998.

Wilson, P. "How Will you do for a Husband?": The Enactment of Wifehood in Shakespeare's Macbeth. MA Thesis in Department of Philology 1, English Philology, Tampere University, 2000. 